\title{
Modelagem do Cloro Residual em Redes de Distribuição - Aplicação ao Sistema de Abastecimento de Santa Maria
}

\author{
Rosalina de David Danieli \\ Companhia Riograndense de Saneamento - CORSAN \\ Maria do Carmo Cauduro Gastaldini \\ Universidade Federal de Santa Maria - UFSM \\ mcarmo@ct.ufsm.br \\ Lidiane Bittencourt Barroso \\ Universidade Regional do Noroeste do Estado do Rio Grande do Sul - UNIJUÍ \\ lidianebarroso@gmail.com \\ Recebido: 03/12/05 - revisado: 17/07/06 - aceito: 31/08/06
}

\section{RESUMO}

Nas redes de abastecimento podem ocorrer vários fatores que degradam a qualidade da água. A portaria MS 518/2004 detalha os procedimentos de vigilância da qualidade da água para manutenção deste padrão. Esta legislação fixa o número e a freqüência de amostragem da água em função da população abastecida, sem estipular a metodologia da escolha dos pontos de amostragem para garantir amostras representativas.

Vários pesquisadores têm se preocupado em desenvolver metodologias para auxiliar na seleção de pontos de amostragem nas redes de distribuição, através da simulação de parâmetros de qualidade da água. O objetivo deste trabalho é utilizar o modelo EPANET para simular a qualidade da água de um setor do sistema de abastecimento de água de Santa Maria. O parâmetro de qualidade da água simulado foi o cloro residual livre.

Foram realizadas campanhas de determinação das características hidráulicas, vazão e pressão, e das concentrações de cloro residual em pontos característicos da rede. O modelo EPANET foi calibrado para previsão dos perfis de pressão e cloro residual. Este modelo, quando perfeitamente calibrado, mostrou ser uma ferramenta eficiente para o controle da qualidade de redes de distribuição.

Palavras-chave: Qualidade da água, redes de distribuição de água, modelo EPANET

\section{INTRODUÇÃO}

Dentre os vários usos da água, o abastecimento doméstico é considerado o mais nobre e prioritário, uma vez que o homem depende de uma oferta adequada de água para a sua sobrevivência. Indispensável à vida, a água também pode ser veículo de microrganismos patogênicos e substâncias tóxicas.

Atualmente, no Brasil, a qualidade da água a ser distribuída e consumida deve atender a requisitos mínimos de potabilidade fixados pela Portaria MS 518/2004, que objetiva proteger a saúde humana.

Mesmo que a qualidade da água tratada esteja de acordo com o padrão de potabilidade, vários fatores podem ocorrer nas redes de abastecimento e em reservatórios, degradando sua qualidade. A Portaria MS 518/2004 detalha os procedimentos de vigilância da qualidade da água para manutenção deste padrão. Esta legislação fixa o número e a freqüência de amostragem da água em função da população abastecida, sem estipular a metodologia da escolha dos pontos de amostragem para garantir amostras representativas.

Várias pesquisas têm sido realizadas com o objetivo de desenvolver metodologias para auxiliar na seleção de pontos de amostragem nas redes de distribuição.

Lee \& Deininger (1992) propuseram a otimização da amostragem, onde a distribuição de pontos de coleta na rede busca a maior representatividade da amostragem (maximização da cobertura), utilizando formulação baseada em programação inteira. 
Vasconcelos Neto et al (2000) aperfeiçoaram a proposta de Lee \& Deininger (1992), propondo modelo, implementado através do programa ORAQUA, objetivando apresentar alternativa para seleção dos pontos de amostragem de forma a maximizar a capacidade de detecção de contaminações por coliformes, que eventualmente ocorram na rede de distribuição.

Medri \& Costa (2001) apresentaram um modelo probabilístico para o controle mensal da qualidade bacteriológica em redes de abastecimento público.

Uma das maneiras de garantir a qualidade da água consumida é através da modelagem matemática da qualidade da água do sistema de distribuição. A simulação da qualidade das águas em redes de distribuição utilizando modelos de previsão da evolução do cloro residual, como os propostos por Rossman (2000) e Sérodes et al. (2001), constituem um eficiente meio de controle da qualidade da água distribuída. O EPANET (Rossman (2000)) é um dos modelos mais utilizados no gerenciamento dos sistemas de distribuição de água potável.

Casagrande \& Sarmento (1997) utilizaram o modelo EPANET para a simulação temporal e espacial da concentração de cloro residual, no sistema de abastecimento de água de JUCU, E.S.

Maier et al (2000) utilizaram o modelo EPANET para estudar dois modelos de decaimento do cloro, o modelo de decaimento simples, de acordo com cinética de primeira ordem e o modelo que considera o decaimento na fase líquida e nas paredes, usado no EPANET.

O objetivo deste trabalho é calibrar o modelo EPANET para um sub-setor do sistema de abastecimento de água de Santa Maria. O parâmetro de qualidade da água simulado é o cloro residual livre. Este modelo calibrado é ferramenta útil na gestão da qualidade da água da rede de abastecimento.

\section{SETOR DE DISTRIBUIÇÃo DE ÁGUA}

A pesquisa foi desenvolvida no setor de distribuição de água do bairro Nossa Senhora de Lourdes e suas imediações, na cidade de Santa Maria - RS. Este setor está estanque hidraulicamente sendo o suprimento de água feito por um único nó. A ocupação é predominantemente residencial, possuindo escolas, supermercados e um hospital. A rede de abastecimento é formada por tubulações de PVC e fibrocimento com extensão de 28.328 m, 4439 economias, em julho de 2003.
O gerenciamento da pressão é feito por uma válvula redutora de pressão (VRP) com unidade controladora para modelação temporal, mantendo o controle permanente das pressões da rede em padrões preestabelecidos.

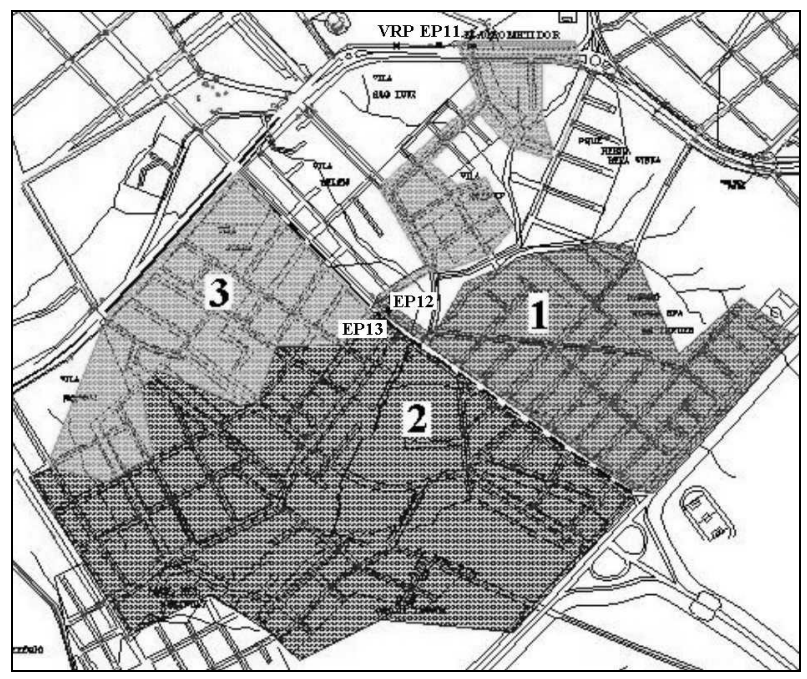

Figura 1 - Setor de Abastecimento, CORSAN (2002).

O setor opera com três estações pitométricas (EP11, EP12 e EP13) instaladas para medir vazão e pressão nos sub-setores 1, 2 e 3 , figura 1 .

\section{MODELO EPANET}

Os modelos matemáticos de qualidade da água objetivam determinar a distribuição espacial e temporal dos constituintes na água. Dentre os modelos disponíveis, um dos mais utilizados no gerenciamento dos sistemas de distribuição de água potável é o modelo EPANET, de domínio público, desenvolvido pela Agência de Proteção Ambiental Americana.

EPANET é um modelo dinâmico de simulação hidráulica e do comportamento de qualidade de água em sistemas de distribuição de água. Considera as variações horárias das características da operação de um sistema público urbano de abastecimento, o qual tem a capacidade de rastrear a vazão de água em cada trecho da rede, a pressão em cada nó, o nível da água nos reservatórios de jusante, a concentração de um constituinte químico ao longo da rede, durante um período de tempo.

A utilização do modelo EPANET exige o conhecimento dos componentes físicos e não físicos do setor da rede de distribuição. A configuração dos 
componentes físicos exigiu os seguintes procedimentos:

- Lançamento dos nós, reservatório, tubulações e válvula redutora de pressão, conectados e formando a rede de distribuição;

- Determinação das propriedades dos nós: cota geométrica, demanda inicial de água, coeficientes de perdas, coeficientes de variabilidade da demanda dos sub-setores 1,2 e 3 .

- Determinação das propriedades das tubulações: diâmetro, comprimento, coeficiente de rugosidade.

Os componentes não físicos descrevem o comportamento e os aspectos operacionais do sistema e são os padrões de tempo. Estabeleceu-se um conjunto de coeficientes de variabilidade de demanda em intervalos de tempo de 5 minutos; e o modo de controle, fornecendo-se as regras de regulagem da válvula redutora de pressão.

As equações que o EPANET utiliza para simular a qualidade da água baseiam-se nos princípios da conservação da massa conjugados com leis cinéticas de reação.

Uma substância dissolvida é transportada ao longo de um tubo com a velocidade média do escoamento, sujeita a uma taxa de reação (crescimento/decaimento). A dispersão longitudinal é um mecanismo de transporte pouco importante e é desprezada. O transporte advectivo num tubo é dado pela equação (1).

$\frac{\partial \mathrm{C}_{\mathrm{i}}}{\partial \mathrm{t}}=-\mathrm{u}_{\mathrm{i}} \frac{\partial \mathrm{C}_{\mathrm{i}}}{\partial \mathrm{x}}+\mathrm{r}\left(\mathrm{C}_{\mathrm{i}}\right)$

onde: $\mathrm{C}_{\mathrm{i}}$ é a concentração do constituinte na tubulação i em função da distância x e do tempo t $\left(M^{-} L^{-3}\right), u_{i}$ é a velocidade média do escoamento na tubulação i(L.T ${ }^{1}$ ), r é a taxa de reação que depende da concentração (M.L $\left.{ }^{-3} \cdot \mathrm{T}^{-1}\right)$.

As reações podem ocorrer no interior do escoamento, entre espécies químicas presentes na água, ou na interface com as paredes das tubulações ou dos reservatórios. O EPANET simula as reações que ocorrem no interior do escoamento utilizando cinéticas de ordem $\mathrm{n}$, onde a taxa de reação instantânea depende da concentração, de acordo com a equação (2).

$\mathrm{r}=\mathrm{K}_{\mathrm{b}} \mathrm{C}^{\mathrm{n}}$ onde: $\mathrm{K}_{\mathrm{b}}$ é o coeficiente de reação no interior do escoamento (positivo em reações de crescimento e negativo nas de decaimento), C é a concentração do constituinte (M.L $\left.{ }^{-3}\right)$, n é a ordem da reação.

No caso da modelagem do decaimento do cloro residual, o decaimento é de primeira ordem, $\mathrm{n}=$ $1 \mathrm{e} \mathrm{K}_{\mathrm{b}}<0$.

Durante o mecanismo de transporte nas tubulações, as substâncias dissolvidas podem ser transportadas para a parede e reagir com materiais, como os produtos de corrosão ou biofilme, que se encontram junto ou na parede da tubulação. A área de tubulação disponível para reação e a taxa de transferência de massa entre a fase líquida e a parede também influenciam a taxa de reação. $\mathrm{O}$ raio hidráulico determina o fator de forma. $\mathrm{O}$ efeito de transferência de massa pode ser representado por um coeficiente de transferência de massa, cujo valor depende da difusão molecular das espécies reativas e do número de Reynolds do escoamento (Rossman, Clark \& Grayman, 1994). Para leis cinéticas de $1^{\underline{a}}$ ordem, a taxa de reação na tubulação pode ser traduzida pela expressão 3:

$r=\frac{2 K_{w} K_{f} C}{R\left(K_{w}+K_{f}\right)}$

onde: $\mathrm{K}_{\mathrm{w}}$ é o coeficiente de reação na parede $\left(\mathrm{L} . \mathrm{T}^{-1}\right)$, $\mathrm{K}_{\mathrm{f}}$ é o coeficiente de transferência de massa $\left(\mathrm{L}^{\mathrm{T}} \mathrm{T}^{-1}\right)$, $\mathrm{R}$ é o raio da tubulação (L).

Os coeficientes de transferência de massa são usualmente expressos em termos do número adimensional de Sherwood (Sh):

$\mathrm{K}_{\mathrm{f}}=\mathrm{Sh} \frac{\mathrm{D}}{\mathrm{d}}$

onde: D é a difusão molecular da espécie a ser transportada $\left(\mathrm{L}^{2} \mathrm{~T}^{-1}\right)$, d é o diâmetro da tubulação (L).

Em regime laminar, o número de Sherwood médio ao longo do comprimento (L) de uma tubulação pode ser expresso pela equação:

$\mathrm{Sh}=3,65+\frac{0,0668(\mathrm{~d} / \mathrm{L}) \operatorname{Re} \mathrm{Sc}}{1+0,04[(\mathrm{~d} / \mathrm{L}) \operatorname{Re} \mathrm{Sc}]^{2 / 3}}$

onde: Re é o número de Reynolds, Sc é o número de Schmidt (viscosidade cinemática da água dividida pela difusão molecular do elemento químico). 
Para escoamento turbulento, a correlação empírica de Notter \& Sleicher (1971) apud Rossman (2000) pode ser utilizada:

$$
\mathrm{Sh}=0,0149 \operatorname{Re}^{0,88} \mathrm{Sc}^{1 / 3}
$$

Os coeficientes $\mathrm{K}_{\mathrm{b}}$ e $\mathrm{K}_{\mathrm{w}}$ devem ser fornecidos pelo usuário do modelo. Para a modelagem do decaimento do cloro, a reação é de primeira ordem e $\mathrm{K}_{\mathrm{w}}$ pode variar entre 0 e $1,5 \mathrm{~m} /$ dia.

O EPANET permite editar dados de entrada do sistema, simulando a qualidade da água e variáveis hidráulicas e mostrando os resultados numa série de formatos, dentre os quais mapas coloridos do sistema, tabelas de dados, gráficos de série de tempo e traçado de contorno.

\section{DESENVOLVIMENTO EXPERIMENTAL}

A utilização do modelo EPANET requer a definição precisa do aspecto físico e operacional do sistema, a calibração hidráulica e a verificação da qualidade da água, neste caso, foi utilizado o cloro residual livre.

Por problemas operacionais, uma vez que o setor é extenso, realizou-se o monitoramento no subsetor 1, possibilitando, assim, a coleta de amostras em intervalos de 1 hora. A figura 2 mostra a localização dos pontos de teste.

Os testes de vazão foram efetuados com tubo Pitot tipo Cole, acoplado a registrador gráfico, no trecho 21. Os de pressão foram executados com coletores de dados Metrolog, nos pontos 22, inicial, 67, intermediário, 59 e 35, ponta de rede.

As concentrações de cloro foram determinadas através de Colorímetro Microprocessado Pocket cloro digital com leitura direta em cloro livre, na faixa de 0 a $2 \mathrm{mg} / \mathrm{L}$, nos pontos 20, 24, 67, 39 e 56. Estes dados foram coletados em intervalos de tempo de 1 hora, sendo possível devido à pequena distância entre os pontos.

A partir do cadastro comercial da Companhia Riograndense de Saneamento (CORSAN) obteve-se o número de economias controladas e os consumos medidos, referentes ao sub-setor 1 . Determinou-se, então, a demanda do sub-setor 1 , como:

$\mathrm{D}_{\mathrm{M}}=\frac{\mathrm{V}_{\mathrm{D}} \cdot \mathrm{k}_{1} \cdot \mathrm{k}_{2}}{\mathrm{Ec} \cdot 86,4}=0,017287 \mathrm{~L} / \mathrm{s} /$ econ. onde: $\mathrm{D}_{\mathrm{M}}$ é a demanda no sub-setor $1, \mathrm{~V}_{\mathrm{Di}}$ é o volume diário no sub-setor $1\left(\mathrm{~V}_{\mathrm{Di}}=515 \mathrm{~m}^{3} / \mathrm{dia}\right), \mathrm{Ec}_{\mathrm{i}}$ é o $\mathrm{n}^{\mathrm{o}}$ de economias controladas no sub-setor $1 \quad\left(\mathrm{Ec}_{\mathrm{i}}=\right.$ 631), 86,4 é o fator de transformação de unidades, $\mathrm{k}_{1}$ é coeficiente do dia de maior consumo, e $\mathrm{k}_{2}$ é da hora de maior demanda.

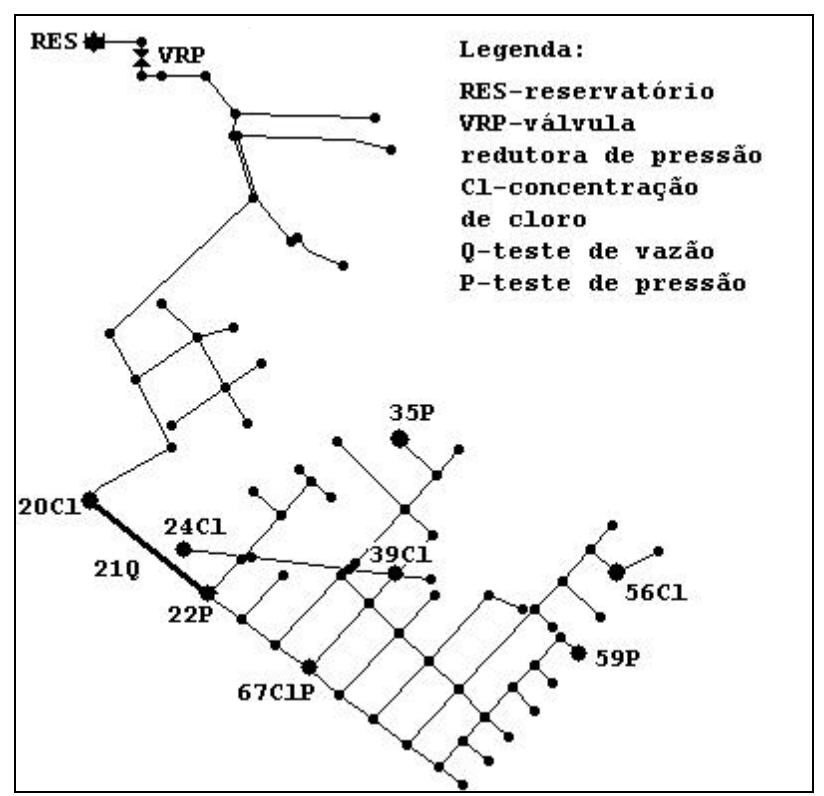

Figura 2 - Localização dos pontos e trechos de teste.

Para a cidade de Santa Maria, os valores fornecidos pela CORSAN são: $\mathrm{k}_{1}=1,22$ e $\mathrm{k}_{2}=1,50$.

$\mathrm{O}$ valor da constante cinética $\mathrm{K}_{\mathrm{b}}$, para reações de primeira ordem, pode ser estimado a partir de ensaios em laboratório, colocando uma amostra de água numa série de garrafas de vidro não reativas e analisando o conteúdo de cada garrafa em diferentes intervalos de tempo pré-determinados. Se a reação é de primeira ordem, a representação gráfica dos valores de $\log (C t / C o)$ em função do tempo, permite obter uma linha reta onde $C t$ é a concentração no instante t e Co é a concentração no instante inicial. $\mathrm{O}$ valor de $\mathrm{K}_{\mathrm{b}}$ é estimado a partir da inclinação da reta (Rossman (2000)).

$\mathrm{O}$ coeficiente $\mathrm{K}_{\mathrm{b}}$ foi determinado segundo esta metodologia. A amostragem foi realizada para o ponto 39, ponto intermediário, obtendo-se o valor $\mathrm{K}_{\mathrm{b}}=-0,1046 /$ dia.

A figura 3 mostra as vazões medidas na entrada do sub-setor 1 , na campanha realizada no dia 31/07/2003.

Observa-se que as vazões diminuem à noite e aumentam ao amanhecer, conforme esperado. 
A figura 4 mostra as pressões medidas, nos pontos de amostragem, na campanha realizada no dia $31 / 07 / 2003$.

Os gráficos das pressões mostram um pico após as 6:00 h, coincidindo com a abertura da válvula redutora de pressão e uma queda às 22:00 h, quando a válvula sofre manobra de fechamento. A maior pressão ocorre no ponto 22, entrada do subsetor, e a menor, no ponto 59, ponto de maior cota e ponta de rede.

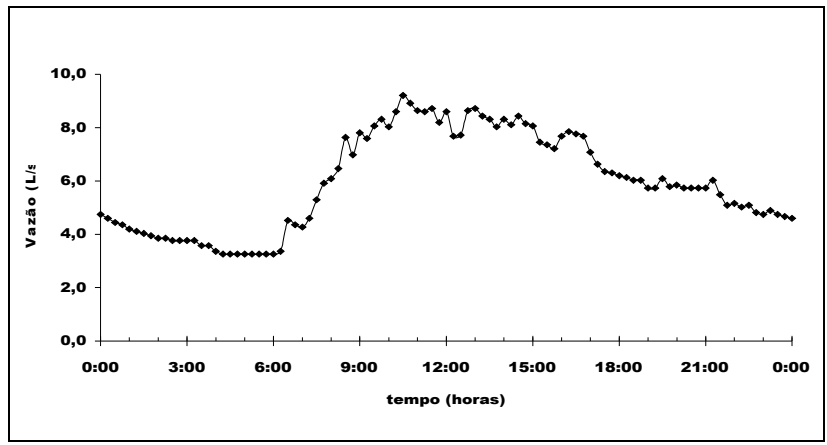

Figura 3 - Vazão observada na entrada do sub-setor 1.

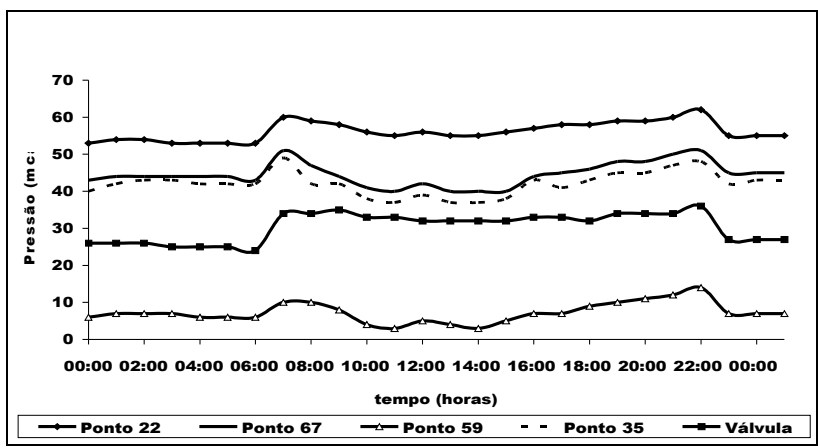

Figura 4 - Pressões observadas nos pontos amostrados.

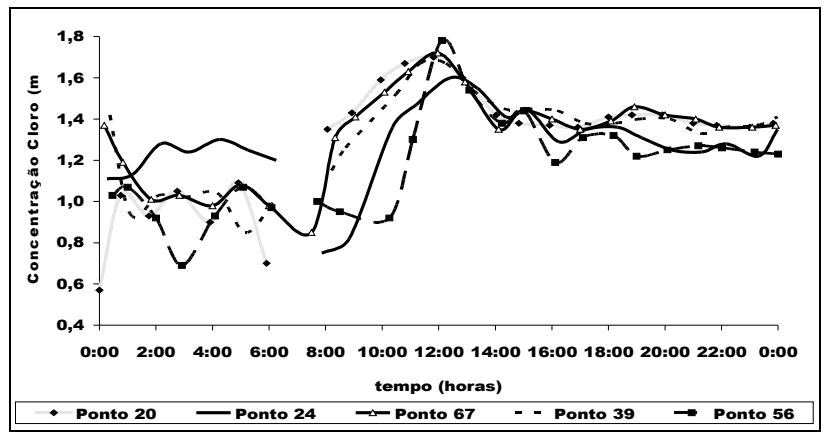

Figura 5 - Concentrações de cloro nos pontos amostrados.
A figura 5 mostra as concentrações de cloro residual livre, nos pontos de amostragem, na campanha realizada no dia 31/07/2003.

Observa-se tendência a menores valores no período noturno, coincidindo com menores vazões; e concentrações mais elevadas no período diurno, maiores vazões.

\section{RESULTADOS}

Para previsão das concentrações de cloro o modelo EPANET deve inicialmente ser calibrado para previsão das vazões e pressões.

A figura 6 mostra os valores observados e simulados pelo modelo EPANET das vazões, no trecho 21, entrada do sub-setor 1 .

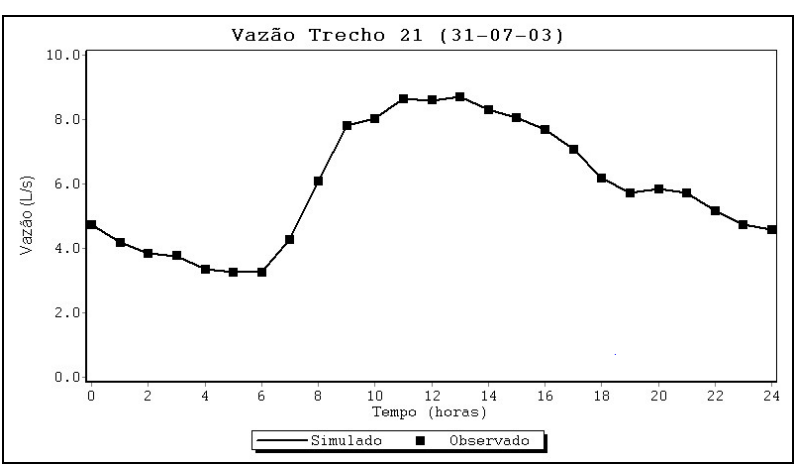

Figura 6 - Vazões simuladas e observadas na entrada do sub-setor 1 .

As figuras 7, 8, 9 e 10 mostram as pressões medidas e as previstas pelo modelo EPANET.

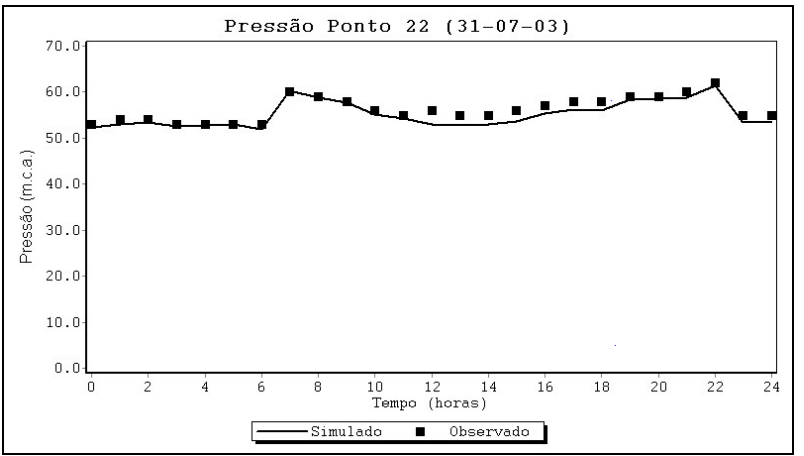

Figura 7 - Pressões simuladas e observadas na entrada do sub-setor 1 . 


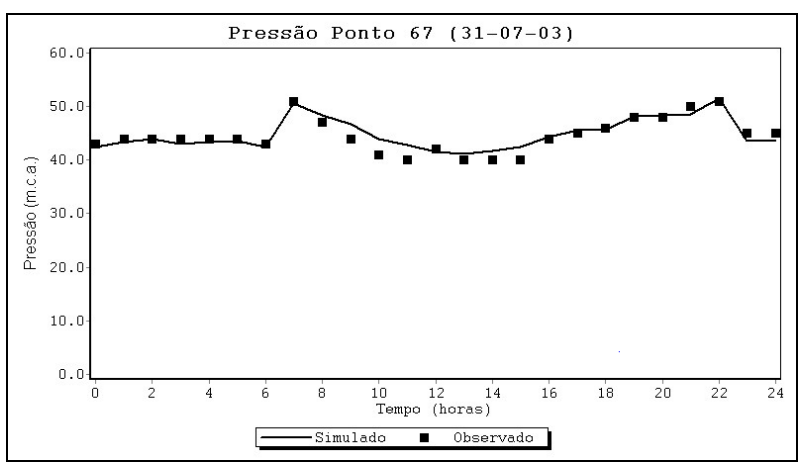

Figura 8 - Pressões simuladas e observadas no ponto 67.

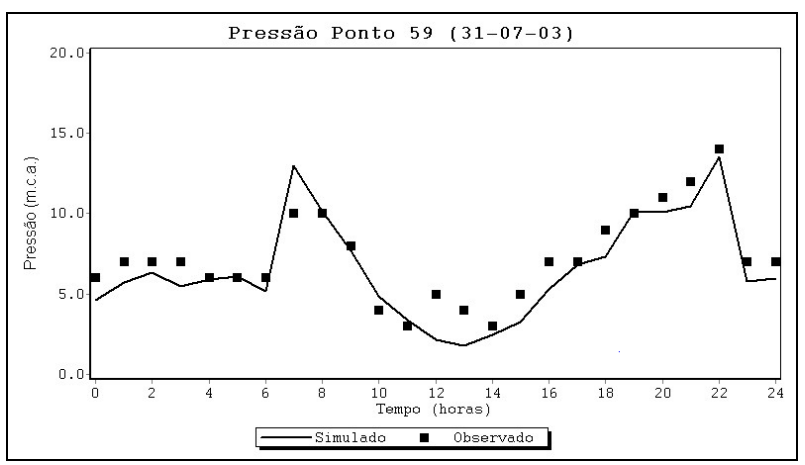

Figura 9 - Pressões simuladas e observadas no ponto 59.

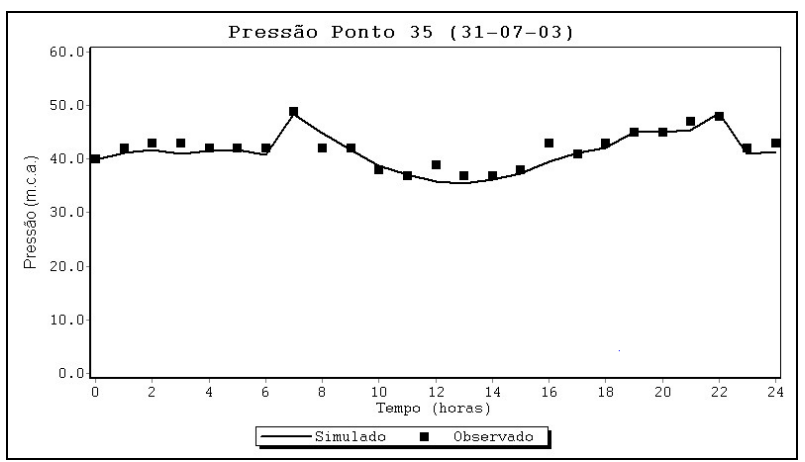

Figura 10 - Pressões simuladas e observadas no ponto 35.

A calibração das pressões teve erro inferior a $2 \%$, em todos os pontos, ficando dentro do nível aceitável de calibração proposto por Walski, Chase \& Savic (2001), um erro máximo de 2 m.c.a. ou $15 \%$ da carga máxima.

Para a calibração do cloro residual adotouse $\mathrm{K}_{\mathrm{b}}$ constante e variou-se os valores de $\mathrm{K}_{\mathrm{w}}$.

O coeficiente de reação no interior do escoamento $\left(\mathrm{K}_{\mathrm{b}}\right)$, determinado experimentalmente, foi adotado constante para todo o sub-setor igual a 0,1046/dia.
De acordo com Walski, Chase \& Savic (2001) os valores dos coeficientes de reação nas paredes $\left(\mathrm{K}_{\mathrm{w}}\right)$ variam entre 0 a $1,524 \mathrm{~m} /$ dia. A análise de sensibilidade realizada mostrou pouca interferência deste coeficiente nos resultados da simulação, adotou-se seu valor igual a zero em todo o sub-setor.

As condições iniciais, dados de entrada do modelo, são uma maneira matemática de incorporar a série histórica de eventos, que determinou o estado da rede no início da simulação. Em vista disto, têm grande importância, além de serem de difícil previsão. Sua determinação em campo para todos os pontos da rede, ao mesmo tempo, é impraticável. Entretanto, o comportamento dinâmico do modelo de qualidade da água pode ser usado para eliminar os problemas associados com a atribuição das condições iniciais. Assim, se a simulação é conduzida num período de tempo suficientemente longo, os valores das condições iniciais atribuídas tornam-se irrelevantes.

Os resultados das concentrações de cloro, calculados pelo modelo EPANET neste trabalho, foram independes das concentrações iniciais fixadas.

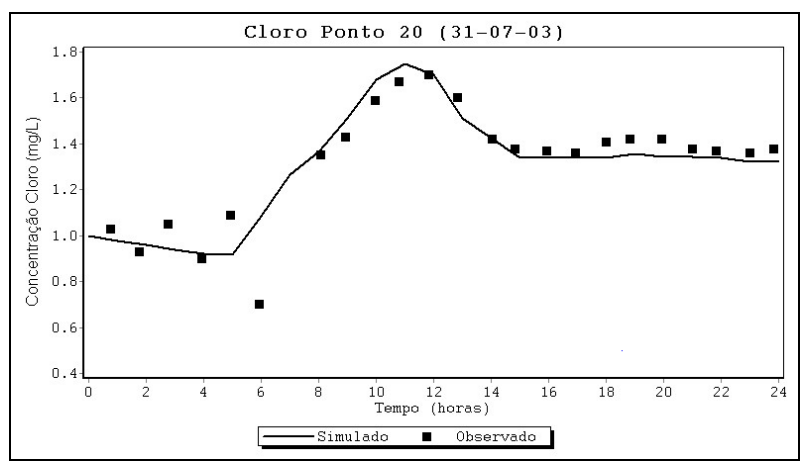

Figura 11 - Concentrações de cloro simuladas e observadas no ponto 20.

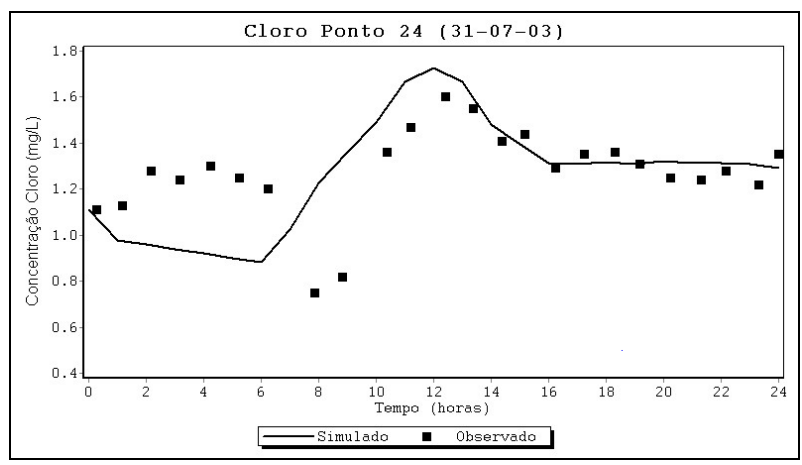

Figura 12 - Concentrações de cloro simuladas e observadas no ponto 24. 


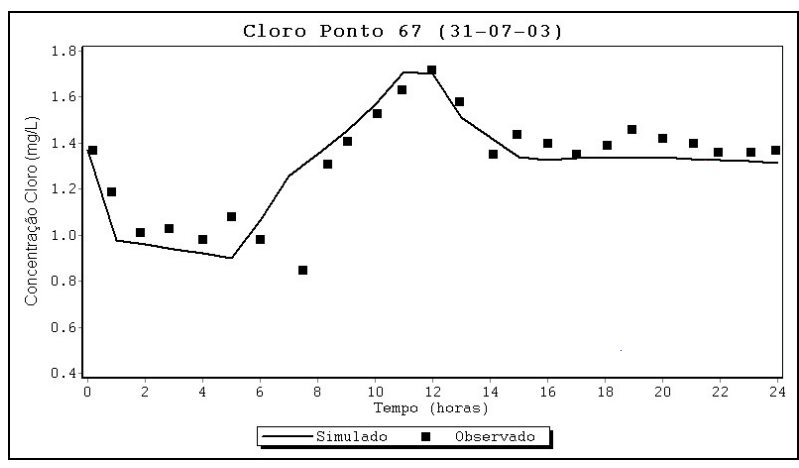

Figura 13 - Concentrações de cloro simuladas e observadas no ponto 67 .

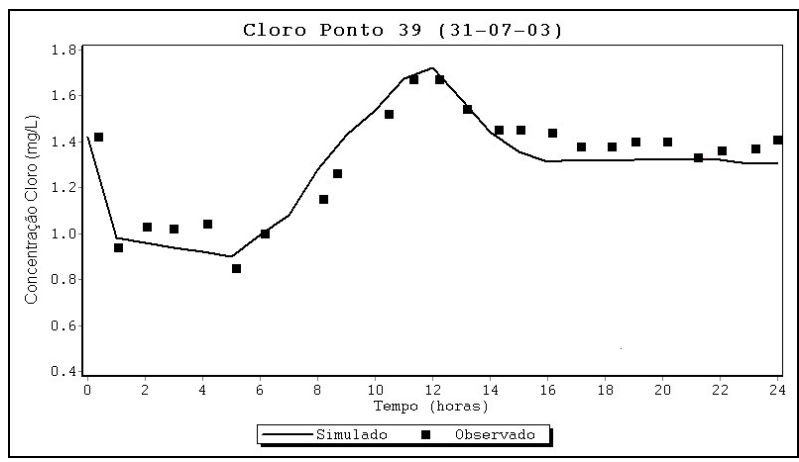

Figura 14 - Concentrações de cloro simuladas e observadas no ponto 39 .

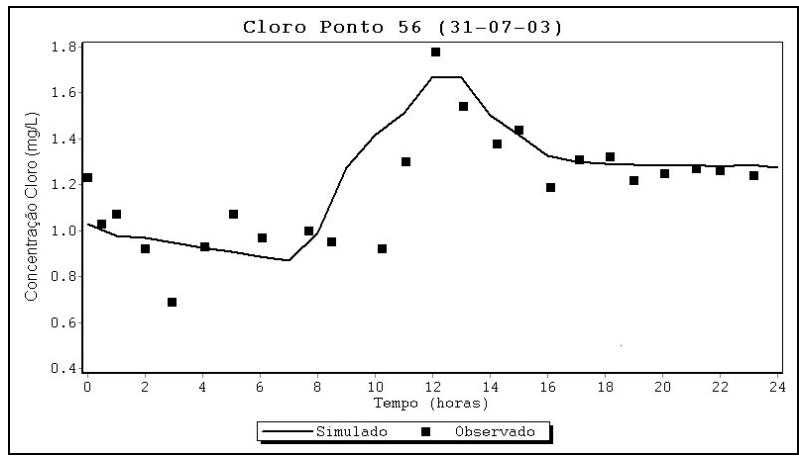

Figura 15 - Concentrações de cloro simuladas e observadas no ponto 56 .

As figuras 11 a 15 mostram os resultados observados e previstos pelo modelo EPANET para as concentrações de cloro.
A análise das figuras 11 a 15 mostra uma boa concordância entre os resultados experimentais e os previstos pelo modelo EPANET. Os pontos que apresentaram piores previsões foram os situados na extremidade da rede, pontos 24 e 56.

Após a calibração do modelo EPANET para simulação do cloro residual livre, este modelo pode ser utilizado para prever concentrações de cloro para diferentes situações da rede.

A Portaria MS 518/2004 recomenda: um teor máximo de cloro residual livre de 2,0 mg/L, em qualquer ponto do sistema de abastecimento; e um teor mínimo de $0,5 \mathrm{mg} / \mathrm{L}$, após a desinfecção, sendo obrigatória a manutenção de, no mínimo, $0,2 \mathrm{mg} / \mathrm{L}$ em qualquer ponto da rede de distribuição.

Para que todos os pontos do sub-setor modelado apresentem concentrações mínimas de 0,2 $\mathrm{mg} / \mathrm{L}$ é necessário que a concentração de cloro na entrada do sub-setor, ponto RES, seja de no mínimo $0,3 \mathrm{mg} / \mathrm{L}$. Se a concentração de cloro neste ponto for de $0,5 \mathrm{mg} / \mathrm{L}$, a rede terá concentrações variando entre 0,41 e $0,50 \mathrm{mg} / \mathrm{L}$. Por outro lado, para que a concentração máxima de $2,0 \mathrm{mg} / \mathrm{L}$ não seja excedida é necessário que a concentração no ponto RES seja no máximo $2,0 \mathrm{mg} / \mathrm{L}$, neste caso as concentrações nos nós variarão entre 1,62 e 2,00 mg/L.

\section{CONCLUSÕES}

Este trabalho foi desenvolvido no setor de distribuição de água do bairro Nossa Senhora de Lourdes e suas imediações, na cidade de Santa Maria - RS. A ocupação é predominantemente residencial. Seu objetivo foi calibrar o modelo EPANET visando prever as concentrações de cloro residual livre.

A utilização do modelo EPANET exigiu levantamento de componentes físicos e não físicos do setor da rede de distribuição.

Foi realizado monitoramento para determinar vazão, pressão, e concentração de cloro residual livre em pontos característicos da rede. O modelo EPANET foi calibrado para previsão dos perfis de vazão, pressão e cloro residual livre, com erro inferior ao nível aceitável proposto pela literatura.

A calibração do modelo para previsão do cloro residual livre mostrou grande dependência de uma calibração hidráulica eficiente, mostrando-se independente das concentrações iniciais.

O modelo EPANET calibrado demonstrou ser uma ferramenta eficiente para o controle da qualidade de redes de distribuição. 


\section{REFERÊNCIAS}

APHA, AWWA, WEF. Standard methods for the Examination of water and Wastewater. 20a ed., Public Health Association Inc., New York, 1998.

CASAGRANDE, J. \& SARMENTO, R. O Uso de Modelagem Matemática de Qualidade da Água no Controle de Cloro Residual em Sistemas de Distribuição. In: $19^{\circ}$ CONGRESSO BRASILEIRO DE ENGENHARIA SANITÁRIA E AMBIENTAL, Foz de Iguaçu. p. 13421353. 1997.

COMPANHIA RIOGRANDENSE DE SANEAMEN-TO - CORSAN (2002) Cadastro da Rede de Distribuição. Porto Alegre.

LEE, B. H. \& DEININGER, R. A. Optimal locations of monitoring stations in water distribution system. Journal of Environmental Engineering, vol. 118, n. 1, p. 4-16, 1992.

MAIER, S.H.; POWELL, R.S. \& WOODWARD, C.A. Calibration and Comparison of Chlorine Decay Models for a Test Water Distribution System. Water Research. Vol 34, n. 8, p. 2302-2309. 2000.

MEDRI, W. \& COSTA, R. H. R. Modelo Probabilístico de Amostragem para Controle da Qualidade Bacteriológica da Água em Redes de Distribuição. Revista Engenharia Sanitária e Ambiental. Vol. 3-4, n. 6, p. 100-107. 2001.

MINISTÉRIO DA SAÚDE. Normas e Padrão de Potabilidade de Águas Destinadas ao Consumo Humano - PORTARIA NN 518 de 25/03/2004, Brasil.

ROSSMAN, L. A., CLARK, R. M. \& GRAYMAN, W. M. Modeling chlorine residuals in drinking-water distribution systems. Journal of Environmental Engineering. vol. 120, n. 4, p. 803-820. 1994.

ROSSMAN, L. A. EPANET 2 Users Manual. Environmental Protection Agency. 200 p. 2000.

SÉRODES, J.B.; RODRIGUEZ, M.J. \& PONTON, A. Chlorcast(:): metholology for developing decision - making tools for chlorine disinfection control. Environmental Modeling \& Software. Vol. 16, p. 53-62. 2001.

VASCONCELOS NETO, J. G., KOIDE, S. \& BRANDÃO, C.C.S. Metodologia para Seleção de Pontos de Amostragem em Redes de Distribuição. In: XXVII CONGRESSO INTERAMERICANO DE ENGENHARIA SANITÁRIA E AMBIENTAL, Porto Alegre, p. 110. 2000.

WALSKI, M. T.; CHASE, V. D. \& SAVIC, A. D. (2001) Calibration Hydraulic Network Models. In: Water Distribution Modeling, Waterbury: Haested, Cap. 6.
Modeling Residual Chlorine in Water Distribution Networks - Application in Santa Maria Watersupply System

\section{ABSTRACT}

Many water quality degradation factors can occur in water-supply systems. Regulation n. 518/2004 of the Ministry of Health details the water quality surveillance procedures to maintain this standard. This regulation establishes the number and frequency of water sampling according to the population supplied without stipulating the method that should be used to choose the sampling points in order to guarantee representative samples.

Many researchers have been involved in developing methodologies to help select sampling points in the distribution systems by simulating water quality parameters. The purpose of this study is to use the EPANET model to simulate water quality in part of the Santa Maria water-supply system. The water quality parameter simulated was free residual chlorine.

Campaigns were conducted to determine the hydraulic characteristics, flow and pressure, and the residual chlorine concentrations in characteristic points of the system. The EPANET model was calibrated to the forecast pressure and residual chlorine profiles. When accurately calibrated, this model proved to be an effective tool for quality control of distribution systems.

Key-words: Water Quality, water distribution networks, EPANET model. 